\title{
MEMORANDUM
}
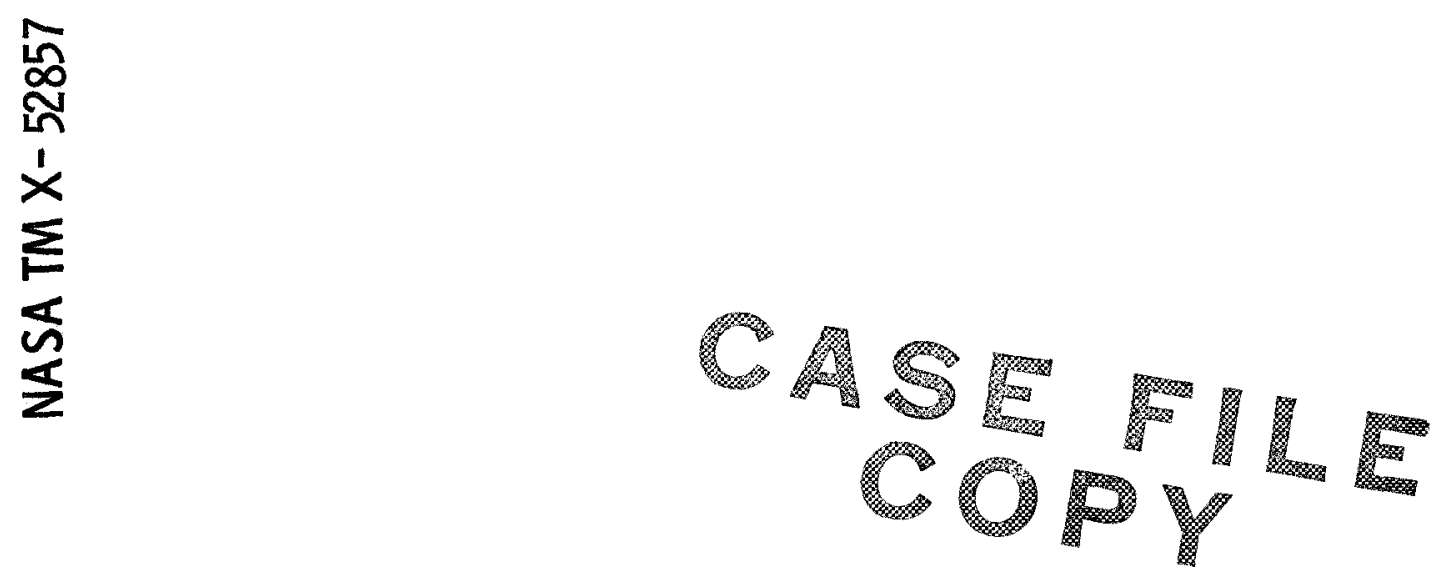

\section{INITIAL PERFORMANCE DATA ON A LOW-POWER MPD ARC THRUSTER WITH A DOWNSTREAM CATHODE}

by James A. Burkhart

Lewis Research Center

Cleveland, Ohio

- TECHNICAL PAPER proposed for presentation at Eighth Electric Propulsion Conference sponsored by the

- American Institute of Aeronautics and Astronautics Stanford, California, August 31 -September 2, 1970 


\title{
INITIAL PERFORMANCE DATA ON A LOW-POWER MPD ARC THRUSTER WITH A DOWNSTREAM CATHODE
}

\author{
by James A. Burkhart \\ Lewis Research Center \\ National Aeronautics and Space Administration \\ Cleveland, Ohio
}

\section{Abstract}

Substantial improvement in the thrust performance of a low-power MPD arc thruster has been achieved in the specific impulse range of 600 to 2100 seconds. The thruster tested utilizes a cathode positioned in the exhaust beam, downstream of the anode, as opposed to the conventional position upstream of the anode. Xenon is the propellant used and testing is conducted in a background pressure of $1.6 \times 10^{-5}$ torr. Operation achieved in the above specific impulse range is at thrust levels from 6 to $16 \mathrm{mN}$, power levels of 180 to 720 watts, and thrust efficiencies of 13 to 24 percent.

\section{Introduction}

A simple, low power magnetoplasmadynamic (MPD) arc thruster is attractive for such auxiliary propulsion applications as satellite station keeping and attitude control. (1) Such a device has been under investigation at the NASA Lewis Research Center.

An electrical discharge is maintained in an axial magnetic field between a cylindrical anode and a cathode centered on the anode axis. The cathode of a conventional MPD arc thruster is located upstream of the anode-discharge region.

Figure 1 is a schematic of the conventional low power MPD arc thruster investigated by Johansen, Bowditch, and Burkhart! $\left.{ }^{2}\right)$ This thruster, operating on xenon propellant, has been found to give the best performance (thrust to power ratio versus specific impulse) for the conventional arrangement of the low power MPD thruster.

Data is presented herein for a new thruster configuration (shown in the photograph of fig. 2) in which the following four major modifications were made:

(1) Cathode placed in the thruster exhaust, downstream of the anode, downstream of the electromagnets, and downstream of the propellant injection points

(2) An orifice plate added to the tip of the hollow cathode

(3) Magnetic pole pieces added to the thruster anode chamber region

(4) Edge wound electromagnets used to produce the magnetic field.

Downstream placement of the cathode is by far the most drastic change in the MPD thruster tested.
Motivations for the Modifications

In Seikel et al. ${ }^{(3)}$ it is shown that theory places a 40 to 70 percent limit on thrust efficiency for specific impulses in the range of 700 to 2000 seconds (when xenon propellant is used). Severe loss to the thruster backplate appears to be a possible source of additional energy loss in many existing thrusters. This backplate loss may explain, in large part, why it is impossible to achieve thrust efficiencies even one-half of tho se predicted by the theory.

Placing the thruster cathode downstream of the anode eliminates an impressed electro static field which tends to accelerate ions toward the backplate causing backplate loss and replaces it with an impressed electrostatic field which tends to accelerate ions out of the exhaust. The position of the cathode in the exhaust was selected from the probe work of Bowditch. ${ }^{(4)}$ Bowditch has shown that ion acceleration in the low-power MPD arc thruster is through an electro static field established in the exhaust by the hot electrons of the plasma as the electrons expand in the magnetic field (nozzle). The position in Bowditch's exhaust where the plasma potential is identical to the cathode potential was selected as the most reasonable place for positioning the downstream cathode tip (without perturbing the potential distribution established in the exhaust by the electron expansion process).

The insertion of pole pieces in the anode chamber was also prompted by a desire to eliminate backplate loss. The field established by the magnets of the conventional thruster diverges away from the thruster axis at the backplate. Hence the magnetic expansion process that Bowditch found important in the exhaust can also be operative in accelerating ions into the backplate. The pole pieces permit shaping of the field such that it converges at the backplate (e.g., acting like a magnetic mirror and inhibiting magnetic expansion) and diverges in the exhaust region. Figure 3 is a map (in iron filings) showing the divergence imparted to the magnetic field of a discharge chamber when pole pieces are used. The example cited in figure 3 is for the SERT II thruster and is taken from Seikel et al. ${ }^{(3)}$

Johansen and Palmer ${ }^{(5)}$ have shown that an edge would aluminum magnet is attractive for use (perhaps in conjunction with a permanent magnet) in producing the magnetic field of an MPD arc thruster. Two such magnets were used on the thruster tested in an attempt to gain experience in fabricating such magnets and to check the theoretical calculations of Johansen and Palmer.

Hollow cathode studies by the author in the conventional low power MPD arc thruster have shown that the addition of an orifice plate to the tip of the hollow cath- 
reason it was decided to also use this type of cathode as the downstream cathode.

\section{Apparatus and Procedure}

Thruster

A photograph giving an overall view of the MPD thruster tested is shown in figure 2. Figure 4 gives a cross-sectional schematic.

Since the best performance obtained with the conventional low-power MPD thruster (Johansen, et al., ref. 2) is with xenon, it was used for all tests reported herein. The propellant flow for most of the testing was split, with the majority ( 80 percent or greater) entering the anode via two feed tubes placed $180^{\circ}$ apart and set perpendicular to the anode surface. The remainder of the flow enters the thruster via the downstream hollow cathode.

Anode dimensions, anode feed tube placement and anode flows are almo st identical to tho se used by Johansen, Bowditch, and Burkhart ${ }^{(2)}$ in studying the conventional low-power MPD arc thruster.

The thruster which was tested weighs $2.88 \mathrm{~kg}(6.4$ lbs.). However, as will be shown later, the upstream magnet appears unnecessary and when removed reduces thruster weight to $2.23 \mathrm{~kg}(4.9 \mathrm{lbs}$.).

\section{Hollow Cathode}

A cross-sectional view of the hollow cathode and support structure is shown in figure 5 . The 2.46 centimeter straight section of hollow tube and the 0.076 centimeter thick orifice plate at the cathode tip are electric discharge machined from a single piece of 2 percent thoriated tungsten. The slight taper of the orifice hole is the result of machining. The minimum hole diameter $(0.025 \mathrm{~cm})$ is at the inside edge of the orifice plate and the maximum hole diameter $(0.033 \mathrm{~cm})$ is at the cathode flow exit plane.

As indicated in figure 5, the upper portion of the downstream cathode support structure is a hollow tube that also supplies cathode propellant, when cathode propellant is used. It is made of tantalum as is the wire supporting the cathode from the bottom of the thruster body. Both tantalum structures are at cathode potential and alined vertically in an attempt to keep electrical symmetry.

During actual thruster operation, ion bombardment of the thoriated tungsten orifice plate keeps the cathode tip heated to a temperature (approximately $1850^{\circ} \mathrm{K}$ ) which is sufficient to maintain the thruster discharge current. The tantalum tube and tantalum wire supporting the actual cathode structure remain a relatively cold bluish gray during normal operation.

When cathode propellant is used, it leaves the cathode from a small orifice in the cathode tip and actually flows out of the cathode in an upstream direction, relative to the exhaust beam.
Cathode propellant is always used to start the discharge. The discharge current attaches either at the inside diameter of the orifice hole or else slightly behind it, inside the hollow tube, and remains there even if the cathode flow is subsequently removed.

\section{Electromagnets}

Figure 6 is a sketch of a single turn of the edge wound magnets used. Each turn is quite thin $0.010 \mathrm{~cm}$ or 0.004 in.). Each of the two electromagnets consists of 360 such turns joined together by overlapping one turn $0.3 \mathrm{~cm}$ with the next turn and resistance welding the seam. The assembled magnets are then anodized to insulate them.

Each magnet produces a field of 0.02 tesla at its center for a current of 4 amperes and a voltage of 12 volts. Magnet design and operation are almo st identical to that shown for the $3.75 \mathrm{~cm}$ radius magnet in table I of Johansen and Palmer ${ }^{(5)}$ except that the magnet has a packing fraction of only 0.63 .

\section{Magnetic Pole Pieces}

For the MPD thruster tested, the set of pole pieces (1020 low carbon steel) used are shown on the schematic of figure 4. The upstream pole piece is made of two pieces welded together. The first is a thin $(0.075 \mathrm{~cm})$ circular disk with an outside diameter of $13.2 \mathrm{~cm}$ and an inside diameter of $3.96 \mathrm{~cm}$. The second part is a thin wall $(0.075 \mathrm{~cm})$ right circular cylinder with an outside diameter of $3.96 \mathrm{~cm}$ and a length of $6.58 \mathrm{~cm}$. One end of the cylinder is welded to the inside diameter of the disk.

When placed in the thruster, the cylindrical part of the pole piece extends from the back of thruster deep into the anode chamber. A boron nitride insulating cap is placed over the downstream end of the cylinder to inhibit particle diffusion and/or acceleration into the inside of the cylinder.

As can be seen in figure 4, the exhaust end pole piece is basically a thin circular disk with a bevel imparted to the edge of the inside diameter. The outside diameter is $13.2 \mathrm{~cm}$. The diameter at which the bevel begins is $5.97 \mathrm{~cm}$. The inside diameter (at end of bevel) is $5.41 \mathrm{~cm}$. The beveled edge makes an angle of $24 \mathrm{de}-$ grees with the thruster axis.

Most of the data presented later is with a direct current of 4 amperes on the exhaust end magnet and no current on the upstream magnet. A plot of the axial component of the magnetic flux density for this case is shown in figure 7 .

Ground Screen

Tests were conducted to check the influence of placing a ground screen about the entire thruster except for the exhaust opening and the cathode structure. This screen is shown in the photograph of figure 8. Thrust data were taken with this ground screen at ground (the vacuum tank potential), at cathode potential and with it 
floating.

\section{Power Supply System}

Figure 9 gives the schematic of the circuit used to supply power to the discharge. A radio frequency arc starter is used to initiate the discharge but is removed once the discharge.reaches steady state.

\section{Vacuum Tank}

Experiments were conducted in a 1.5 meter diameter by 5.0 meter long vacuum tank. Background pressure was maintained at $1.6 \times 10^{-5}$ torr or less for all data taken. The thruster was mounted at one end of the tank and the exhaust plume extended along the tank's longest dimension.

\section{Thrust Stand}

A schematic of the parallelogram-pendulum thrust stand used to measure all thrust data is shown in figure 10.

The four pendulum struts (two on each side of stand) are attached to the reference platform by low friction ball bearings rated for low vacuum use. Likewise the weighted pan used for thruster mounting is attached to the struts by similar ball bearings. Static friction loading has been experimentally verified to be less than 1.0 percent of the lowest thrust level measured.

The center of gravity of the movable part of the stand is below the reference platform. The mass of the stand plus the mass of the thruster acting through this point are the restoring forces when the thruster is operating.

For the thrust levels involved, the stand moves through very small angles and deflection of the stand is linearly proportional to thrust. This linear displacement is sensed electronically by a linear voltage differential transformer (LVDT). The alternating current signals of the LVDT are conditioned (demodulated) by the signal conditioner and displayed on a strip chart.

The system is calibrated by a series of three weights suspended by very thin string (of negligible weight) from a moment arm of known length (L/2). The weights normally hang free but can be picked up in a small pan mounted inside the vacuum tank. When picked up, each weight deflects the stand an amount equal to the deflection produced by $9.8 \mathrm{mN}$ of thrust.

A single counterweight, equivalent in mass to the total of the three calibration weights (and having an adjustable mount), is mounted from a moment arm at the oppo site end of the stand. Its position is adjusted to mechanically zero the stand.

Calibration of the stand is repeatable to within 3 percent of the full scale deflection of $29.4 \mathrm{mN}$. Linearity, including hysteresis due to all causes (such as the spring constants of the power leads), is also repeatable to within 3 percent of the full scale deflection.
A copper plate suspended from the weighted thruster pan and moving between the poles of a permanent magnet provides damping for the stand under dynamic conditions.

\section{Experimental Procedure}

Propellant flow rates are set by varying the pressure upstream of fixed size "calibrated leaks." Both the anode and cathode propellant lines have a shut-off valve located in the section of feed line downstream of the leaks, but upstream of the thruster.

To initiate the thruster discharge, these two shutoff valves are closed, allowing propellant pressure to build up in the section of line between the "calibrated leak" and the valve itself. The pressure is usually allowed to build up to a value estimated to be about $1 / 10$ th of an atmo sphere. The high frequency arc starter is then switched into the discharge circuit (see fig. 9) and the discharge supply turned on. The shut-off valves are now opened, allowing the pressures in the lines between the "calibrated leaks" and the thruster to decay. As the pressure decays, ignition occurs when the pressure satisfies Paschen breakdown conditions.

After the discharge is initiated, the high frequency arc starter is switched out of the circuit. The discharge supply and flow rates are adjusted to the experimental conditions desired.

Prior to taking each thrust point, a calibration is taken by picking up one of the calibration weights and noting the net displacement as recorded on the strip chart. Also the thruster discharge is turned off (after noting the thrust displacement) to determine the exact zero of the stand.

Measurements are then made of net thrust stand deflection, discharge current, discharge voltage, magnet current, magnet voltage, tank pressure, and propellant flow rate. These parameters are then used to calculate specific impulse and thrust efficiency given, respectively by

$$
\begin{gathered}
I_{s p}=\frac{T}{\dot{m g}} \\
\eta_{T}=\frac{T^{2}}{2 \dot{m} P_{D}}
\end{gathered}
$$

where $\mathrm{T}$ is the thrust, $\dot{\mathrm{m}}$ the mass flow rate, $\mathrm{g}$ the gravitational constant, and $P_{D}$ the power supplied to the discharge. The thrust efficiency $\eta_{\mathrm{T}}$ does not include magnet power.

Each thrust point taken was also checked with the thrust stand locked down so that no deflection could occur. The maximum signal registered under this condition was well under 0.5 percent of reading with stand unlocked.

\section{Results and Discussion}

Initially, a rapid qualitative study of thrust varia- 
ducted for the low power MPD thruster with a downstream cathode. This was merely done by observing trends on the thrust stand strip chart. Quantitative data was then taken at parameter combinations that appeared near optimum (highest thrust efficiency at attractive values of specific impulse) from this qualitative survey.

Qualitatively the following were examined over a power range up to 1 kilowatt:

(1) Optimum shape of the magnetic field

(2) Optimum field strength

(3) Performance vs. mass flow for various cathode flows

(4) Effect of adding a screen and effect of how the screen is biased.

The results of these qualitative tests indicated that:

(1) The optimum magnetic field shape was obtained using only the downstream coil.

(2) To obtain the best performance required a current of approximately 4 amperes (dc) in this downstream coil. Somewhat higher currents (e.g. , 6 and 8 amperes) neither improved nor deteriorated the performance.

(3) The performance improves at all specific impulses up to 2000 . seconds with increasing mass flow up to a mass flow of approximately $0.8 \mathrm{mg} / \mathrm{sec}$.

(4) The best performance occurs at zero cathode flow.

(5) Thruster performance is not very sensitive to the presence of the screen grid or its bias voltage.

(6) The performance of this thruster is substantially superior to the best previous conventional low-power MPD arc thrusters.

The subsequent quantitative data presented in table I and in figures $\mathbf{1 1}$ to $\mathbf{1 6}$ supports the above stated trends.

\section{Comparison with Conventional MPD Thruster}

A set of quantitative data was taken close to the above stated optimums, namely at $0.78 \mathrm{mg} / \mathrm{sec}$ total flow, no cathode flow, a magnetic field using only the exhaust end magnet operated at 4 amperes (see fig. 7) and the ground screen attached to cathode potential. The nume rical data is presented in table $\mathrm{I}(\mathrm{b})$.

Figure 11 compares this near optimum thrust efficiency versus specific impulse curve (for the downstream cathode thruster) to the best thrust efficiency versus specific impulse curve achieved to date for the conventional low power MPD thruster. The data for the conventional low power MPD thruster is taken from figure 18 of Johansen, Bowditch, and Burkhart $\left(^{(2)}\right.$ In that paper(2), the data is plotted as thrust/power versus specific impulse. Thrust efficiency is obtained from that plot by using

$$
\eta_{\mathrm{T}}=\frac{\mathrm{g}}{2}\left(\mathrm{I}_{\mathrm{sp}}\right)\left(\frac{\mathrm{T}}{\mathrm{P}_{\mathrm{D}}}\right)
$$

Figure 12 is plot of thrust versus discharge power (also showing the specific impulses) for this near optimum thrust performance.

Clearly the performance of the downstream cathode thruster in figure 11 is substantially better than the conventional MPD thruster in the specific impulse range of 600 seconds to 2100 seconds. In fact, the conventional low-power MPD thruster has been operated only at very low thrust efficiencies (not shown on fig. 11) for specific impulses above 1400 seconds while the downstream cathode thruster achieves its best performance in the 1400 to 2000 second range.

The exact reasons for this improvement in thrust performance are not known. Additional investigations are needed to isolate and pinpoint the reasons for the superior performance of this downstream cathode thruster.

\section{Performance Versus Mass Flow Rate Variations Quantitative)}

Initially thruster operation was studied with flow rates almo st identical to tho se investigated by Johansen, Bowditch, and Burkhart ${ }^{(2)}$ for the conventional MPD thruster. Flow was split with 0 to 20 percent of the total flow to the cathode and the remainder to the anode.

At total flows appreciably below $0.58 \mathrm{mg} / \mathrm{sec}$, optimum for the conventional MPD thruster with the same size anode, ${ }^{(2)}$ operation was very unstable. The exhaust plume was visually observed to be pulsing and the discharge went out very frequently.- It was impossible to take thrust readings.

As flow was increased, stable operation was finally achieved at $0.57 \mathrm{mg} / \mathrm{sec}(0.48 \mathrm{mg} / \mathrm{sec}$ to anode and 0.09 $\mathrm{mg} / \mathrm{sec}$ to cathode).

Figure 13 shows how performance varies as anode flow is increased with the cathode flow fixed at 0.09 $\mathrm{mg} / \mathrm{sec}$. The thrust efficiency is improved in the specific impulse range of 800 seconds to 1800 seconds as the flow rate is increased from $0.48 \mathrm{mg} / \mathrm{sec}$ to $0.78 \mathrm{mg} / \mathrm{sec}$. For anode flows slightly (e.g., 10 to 20 percent) above 0.78 $\mathrm{mg} / \mathrm{sec}$ no further improvement in performance could be detected. At much higher flows, for example above 1.5 $\mathrm{mg} / \mathrm{sec}$, the thrust efficiency deteriorates drastically (down to 1 percent or 2 percent) and high specific impulse was not achieved.

Table I(g) and $(\mathrm{h})$ gives the discharge electrical parameters, flow rates and thrust levels for the two curves shown in figure 13. As can be seen from this table the electrical discharge operation is characterized by a positive resistance. At the higher flows in which thrust efficiency deteriorates, the discharge behaves more like an arc, operating at a constant voltage of about 50 volts 
Figure 14 shows the effect of cathode flow. Data is shown for no cathode flow and a cathode flow approximately 10 percent of the total flow of $0.87 \mathrm{mg} / \mathrm{sec}$. As can be seen, improvement in the thrust efficiency for the specific impulse range of 800 seconds to 2000 seconds is gained by not using cathode flow.

For cathode flows at 20 percent of total flow, the discharge drops into the low voltage arc type mode, characterized again by badly deteriorated thrust efficiency.

Thrust efficiencies at other values of total mass flow with 10 percent cathode flow and with no cathode flow were spot checked. The no cathode flow condition always corresponds to the higher thrust efficiency.

Performance Versus Ground Screen Variations Quantitative)

The near optimum condition of no cathode flow, a total mass flow of $0.78 \mathrm{mg} / \mathrm{sec}$ and $4 \mathrm{amps}$ current to the exhaust end coil was used to study the effect of adding a ground screen about the entire thruster except for the exhaust opening and cathode structure (e.g., fig. 8). Figure 15 shows how thrust efficiency varies with specific impulse for three different electrical connections of the screen, and for the same operating conditions with no ground screen.

Figure 15 indicates that addition of the screen and the way in which it is biased has little effect on the performance. Compared to the no screen case, the most improvement that can be gained at any specific impulse is about a 1-1/2 percent increase in thrust efficiency and this is done by adding the screen and connecting it to the cathode. The data in table I(a), (b), (c), and (d) indicates that the addition of the ground screen has little effect on the cathode floating voltage.

Performance Versus Magnetic Field Variations (Quantitative)

Since the optimum performance for the low power MPD thruster with a downstream cathode appears to occur with a total mass flow of $0.78 \mathrm{mg} / \mathrm{sec}$, no cathode flow and a ground screen electrically common with the cathode, these conditions were used to study magnetic field variations.

Any use of the upstream magnet, deteriorates thrust. This was verified for a number of data points. Hence the remaining magnetic field studies were restricted to vary ing magnetic field strength by varying the current of only the exhaust end magnetic coil.

At no magnetic field, thrust efficiency is well under $1 / 10$ th of one percent. As the magnetic field of the downstream coil is increased, the amount of thrust generated is negligible until the coil current is about 2 amperes. As the current is increased, the performance improves up to a current of 4 amperes, also the impedance of the discharge increases. Beyond 4 amperes, at 6 , and 8 amperes, no improvement occurs in performance and very little change occurs in the discharge impedance.
Figure 16 compares the performance curve obtained at 2 amperes and at 4 amperes. (This data is also presented in table I(b) and (e).) Even with 2 amperes, a thrust efficiency of 19.6 percent at 1370 seconds can be achieved.

\section{Background Pressure Tests}

The possibility of tank background gas being entrained in the MPD thruster discharge introduces the possibility of error in the total mass flow passing through the thruster. This in turn introduces the possibility of error in the exact value of the thrust efficiency.

To gain insight into this problem, the tank background pressure was intentionally raised above the $1.6 \times 10^{-5}$ torr operating pressure by bleeding xenon gas directly into the tank.

Figure 17 shows the variation of thruster efficiency as a function of background pressure for the thruster operating at two different conditions. As can be seen, the efficiency has a very slight downward trend as the background pressure is raised up to values one order of magnitude higher than the typical operating pressure. Similar trends were obtained for the other specific impulses that were checked.

Thus at the operating pressures of the tank, thruster performance is essentially independent of facility pressure. If anything, performance measurements may be slightly pessimistic compared to performance attainable in space.

\section{Concluding Remarks}

It has been shown that substantial improvement in the thrust performance of a low-power MPD arc thruster can be achieved by modifying the conventional thruster in the following four ways:

1. Cathode placed downstream of the anode

2. Hollow cathode modified by adding an orifice plate to the cathode tip

3. Magnetic pole pieces added to the thruster anode chamber

4. A single edge wound electromagnet used.

No positive proof has been rendered as to the individual contribution of the above four modifications to the improvement in thrust efficiency. The field developed by the edge wound magnet-pole piece combination (and found to be optimum for this thruster) is the most unlikely source of this large performance improvement.

The influence of the orifice plate addition to the hollow cathode is unknown and requires additional investigation. The characteristics of such a discharge are very sensitive to cathode design. ${ }^{(6)}$

Most likely, it can be postulated that downstream placement of the cathode is primarily responsible for the 
thrust efficiency improvement. For with this placement, the impressed electric field between cathode and anode is accelerating ions out of the exhaust instead of into the backplate region.

It is interesting to compare this new thruster configuration to other type plasma thrusters. For example, the Hall Current ion accelerator ${ }^{(7)}$ which makes use of a radial magnetic field to provide acceleration, has a downstream cathode in the electrical discharge chamber. So in a sense, the low power MPD thruster with a downstream cathode is a hybrid of the conventional MPD thruster and the Hall Current ion accelerator.

\section{References}

1. Seikel, G. R., Bowditch, D. N., and Domitz, S., "Application of Magnetic-Expansion Plasma Thrustors to Satellite Station Keeping and Attitude Control Missions," Paper 64-677, Aug. 1964, AIAA, New York, N. Y.

2. Johansen, A. E., Bowditch, D. N., and Burkhart, J. A., "Experimental Performance of a LowPower MPD Arc Thrustor, "Paper 67-50, Jan. 1967, AIAA, New York, N. Y.
3. Seikel, G. R., Connolly, D. J., Michels, C. J., Richley, E. A., Smith, J. M., and Sovie, R. J., "Plasma Physics of Electric Rockets," Plasmas and Magnetic Fields in Propulsion and Power Research, SP-226, 1970, NASA, Washington, D. C., pp. 1-64.

4. Bowditch, D. N. , "Investigation of the Discharge and Exhaust Beam of a Small Arc Plasma Thrustor, " Paper 66-195, Mar. 1966, AIAA, New York, N. Y.

5. Johansen, A. E. and Palmer, R. W., "Lightweight Magnets for MPD Arcs," Paper 67-686, Sept. 1967, AIAA, New York, N. Y.

6. Bechtel, R. T., "Component Testing of a 30Centimeter Diameter Electron Bombardment Thruster, " to be presented at AIAA 8th Elec. Prop. Conf., 1970.

7. Chubb, D. L. and Seikel, G. R., "Basic Studies of a Low Density Hall Current Ion Accelerator," TN D-3250, 1966, NASA, Cleveland, Ohio. 
TABLE I OPERATING PARAMETERS OF THE DOWNSTREAM CATHODE MPD THRUSTER

(a) No ground screen about the thruster, $0.78 \mathrm{mg} / \mathrm{sec}$ total flow, no cathode flow and magnetic field $4 \mathrm{~A}$ downstream coil

\begin{tabular}{|c|c|c|c|c|c|c|}
\hline $\begin{array}{c}\text { Discharge } \\
\text { voltage, } \\
\mathrm{V}\end{array}$ & $\begin{array}{c}\text { Discharge } \\
\text { current, } \\
\mathrm{A}\end{array}$ & $\begin{array}{c}\text { Discharge } \\
\text { power, } \\
\mathrm{W}\end{array}$ & $\begin{array}{c}\text { Thrust, } \\
\mathrm{mN}\end{array}$ & $\begin{array}{c}\text { Specific } \\
\text { impulse, } \\
\text { sec }\end{array}$ & $\begin{array}{c}\text { Thrust } \\
\text { efficiency, } \\
\text { percent }\end{array}$ & $\begin{array}{c}\text { Cathode } \\
\text { voltage } \\
\text { relative } \\
\text { to ground, } \\
\mathrm{V}\end{array}$ \\
\hline 87 & 1.33 & 115 & 3.2 & 420 & 5.7 & -22.0 \\
95 & 1.51 & 143 & 4.3 & 560. & 8.3 & -18.0 \\
116 & 1.58 & 183 & 5.9 & 770 & 12.1 & -17.0 \\
140 & 1.71 & 239 & 7.7 & 1000 & 15.9 & -14.0 \\
162 & 1.81 & 293 & 9.2 & 1200 & 18.5 & -12.0 \\
188 & 1.76 & 331 & 10.1 & 1310 & 19.7 & -14.0 \\
232 & 1.78 & 412 & 12.0 & 1560 & 22.4 & -10.5 \\
315 & 1.80 & 567 & 14.3 & 1850 & 22.9 & -7.0 \\
358 & 1.96 & 702 & 15.2 & 1980 & 21.1 & 0 \\
\hline
\end{tabular}

(b) With ground screen at cathode potential, $0.78 \mathrm{mg} / \mathrm{sec}$ total flow, no cathode flow and magnetic field $4 \mathrm{~A}$ downstream coil

\begin{tabular}{|r|r|r|r|r|r|r|}
\hline 82 & 1.37 & 112 & 2.9 & 370 & 4.7 & -25.0 \\
93 & 1.54 & 143 & 4.2 & 540 & 7.7 & -19.0 \\
110 & 1.63 & 179 & 6.0 & 780 & 12.8 & -17.0 \\
135 & 1.77 & 238 & 8.0 & 1040 & 17.2 & -14.0 \\
158 & 1.86 & 294 & 9.7 & 1270 & 20.6 & -11.7 \\
184 & 1.88 & 346 & 10.7 & 1390 & 21.1 & -11.7 \\
228 & 1.82 & 415 & 12.5 & 1620 & 24.0 & -12.5 \\
317 & 1.81 & 574 & 14.5 & 1880 & 23.4 & -12.5 \\
345 & 2.08 & 718 & 15.8 & 2060 & 22.3 & -0.7 \\
360 & 3.00 & 1080 & 16.4 & 2130 & 15.9 & -22.0 \\
\hline
\end{tabular}

(c) With ground screen floating, $0.78 \mathrm{mg} / \mathrm{sec}$ total flow, no cathode flow and magnetic field $4 \mathrm{~A}$ downstream coil

\begin{tabular}{|r|r|r|r|r|r|r|}
\hline 87 & 1.32 & 115 & 2.9 & 380 & 4.7 & -22.0 \\
99 & 1.50 & 149 & 4.5 & 580 & 8.7 & -18.0 \\
117 & 1.53 & 178 & 5.4 & 710 & 10.5 & -19.0 \\
146 & 1.62 & 237 & 6.7 & 870 & 12.2 & -19.5 \\
170 & 1.71 & 291 & 8.7 & 1130 & 16.7 & -16.5 \\
188 & 1.82 & 342 & 10.5 & 1360 & 20.6 & -14.0 \\
227 & 1.89 & 429 & 12.6 & 1640 & 23.8 & -11.0 \\
310 & 1.98 & 614 & 15.1 & 1960 & 23.7 & -6.0 \\
365 & 3.00 & 1094 & 15.7 & 2050 & 14.4 & -75.0 \\
\hline
\end{tabular}

(d) With ground screen at tank potential, $0.78 \mathrm{mg} / \mathrm{sec}$ total flow, no cathode flow and magnetic field $4 \mathrm{~A}$ downstream coil

\begin{tabular}{|r|r|r|r|r|r|r|}
\hline 89 & 1.24 & 110 & 2.5 & 330 & 3.6 & -26.0 \\
101 & 1.38 & 139 & 3.7 & 480 & 6.2 & -23.0 \\
110 & 1.63 & 179 & 5.3 & 690 & 10.1 & -18.0 \\
141 & 1.72 & 242 & 6.7 & 860 & 11.7 & -19.0 \\
168 & 1.68 & 282 & 8.3 & 1080 & 15.5 & -20.0 \\
191 & 1.77 & 338 & 10.1 & 1310 & 19.1 & -17.0 \\
232 & 1.82 & 422 & 12.2 & 1590 & 22.7 & -15.5 \\
315 & 1.81 & 570 & 14.1 & 1830 & 22.4 & -7.0 \\
\hline
\end{tabular}


TABLE I Concluded. OPERATING PARAMETERS OF THE DOWNSTREAM CATHODE MPD THRUSTER

(e) With ground screen at cathode potential, $0.78 \mathrm{mg} / \mathrm{sec}$ total flow, no cathode flow and magnetic field $2 \mathrm{~A}$ downstream coil

\begin{tabular}{|c|c|c|c|c|c|c|}
\hline $\begin{array}{c}\text { Discharge } \\
\text { voltage, } \\
\text { V }\end{array}$ & $\begin{array}{c}\text { Discharge } \\
\text { current, } \\
\text { A }\end{array}$ & $\begin{array}{c}\text { Discharge } \\
\text { power, } \\
\text { W }\end{array}$ & $\begin{array}{c}\text { Thrust, } \\
\mathrm{mN}\end{array}$ & $\begin{array}{c}\text { Specific } \\
\text { impulse, } \\
\text { sec }\end{array}$ & $\begin{array}{c}\text { Thrust } \\
\text { efficiency, } \\
\text { percent }\end{array}$ & $\begin{array}{c}\text { Cathode } \\
\text { voltage } \\
\text { relative } \\
\text { to ground, } \\
\text { V }\end{array}$ \\
\hline 72 & 1.93 & 139 & 4.2 & 550 & 8.2 & -13.0 \\
91 & 2.08 & 189 & 5.9 & 760 & 11.7 & -14.0 \\
107 & 2.23 & 239 & 7.4 & 960 & 14.4 & -10.5 \\
122 & 2.46 & 300 & 8.9 & 1160 & 16.9 & -7.5 \\
171 & 2.12 & 362 & 10.5 & 1370 & 19.6 & -8.0 \\
208 & 2.22 & 462 & 11.7 & 1520 & 19.0 & -5.0 \\
290 & 2.28 & 662 & 13.8 & 1800 & 18.5 & -1.0 \\
320 & 2.51 & 803 & 15.6 & 2020 & 19.3 & -.5 \\
355 & 3.10 & 1100 & 14.2 & 1840 & 11.7 & -69.0 \\
\hline
\end{tabular}

(f) With ground screen at cathode potential, $0.87 \mathrm{mg} / \mathrm{sec}$ total flow, no cathode flow and magnetic field $4 \mathrm{~A}$ downstream coil

\begin{tabular}{|r|r|r|r|r|r|r|}
\hline 72 & 1.57 & 112 & 3.1 & 370 & 5.1 & -17.5. \\
82 & 1.73 & 142 & 4.4 & 520 & 8.0 & -16.0 \\
93 & 1.93 & 179 & 6.1 & 720 & 11.9 & -13.0 \\
127 & 2.08 & 263 & 9.0 & 1050 & 17.7 & -10.0 \\
145 & 2.16 & 313 & 10.4 & 1220 & 20.0 & -10.0 \\
162 & 2.23 & 361 & 11.5 & 1350 & 21.2 & -8.0 \\
208 & 2.18 & 453 & 13.6 & 1600 & 23.5 & -6.7 \\
300 & 2.17 & 652 & 16.1 & 1890 & 22.9 & -8.0 \\
298 & 3.15 & 938 & 17.3 & 2040 & 18.6 & -16.0 \\
\hline
\end{tabular}

(g) No ground screen, cathode flow of $0.09 \mathrm{mg} / \mathrm{sec}$, anode flow of $0.48 \mathrm{mg} /$ sec, and magnetic field $4 \mathrm{~A}$ downstream coil

\begin{tabular}{|r|r|r|r|r|r|r|}
\hline 124 & 0.92 & 114 & 3.4 & 610 & 8.9 & -32.0 \\
148 & .98 & 145 & 4.6 & 820 & 12.8 & -25.0 \\
192 & .99 & 190 & 5.8 & 1020 & 15.2 & -29.0 \\
245 & 1.12 & 274 & 7.2 & 1290 & 16.8 & -14.0 \\
307 & 1.12 & 344 & 8.2 & 1450 & 17.0 & -13.0 \\
\hline
\end{tabular}

(h) No ground screen, cathode flow of $0.09 \mathrm{mg} / \mathrm{sec}$, anode flow of $0.78 \mathrm{mg} /$ sec, and magnetic field of $4 \mathrm{~A}$ downstream coil

\begin{tabular}{|r|r|r|r|r|r|r|}
\hline 93 & 1.12 & 106 & 2.7 & 320 & 4.0 & -28.0 \\
93 & 1.57 & 146 & 4.4 & 510 & 7.5 & -17.0 \\
109 & 1.71 & 186 & 6.1 & 710 & 11.3 & -14.5 \\
141 & 1.76 & 248 & 7.8 & 910 & 14.1 & -14.0 \\
188 & 1.83 & 344 & 10.7 & 1250 & 19.2 & -12.0 \\
230 & 1.82 & 418 & 12.0 & 1410 & 19.9 & -9.5 \\
315 & 1.84 & 580 & 14.1 & 1640 & 19.6 & -4.5 \\
360 & 1.93 & 695 & 15.4 & 1790 & 19.5 & 0 \\
\hline
\end{tabular}




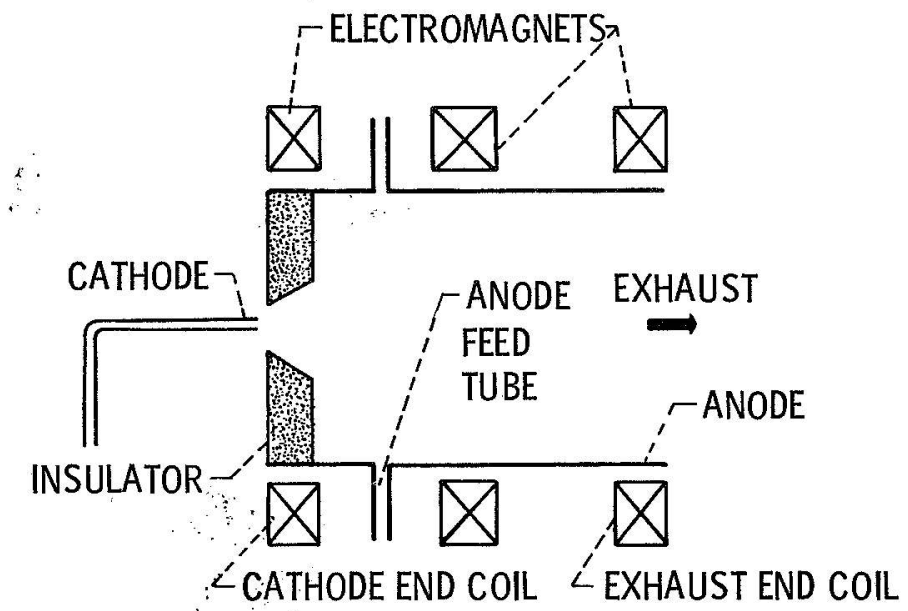

Figure 1. - Schematic of the low power MPD arc thruster (conventional arrangement) investigated by Johansen et al. (ref. 2).

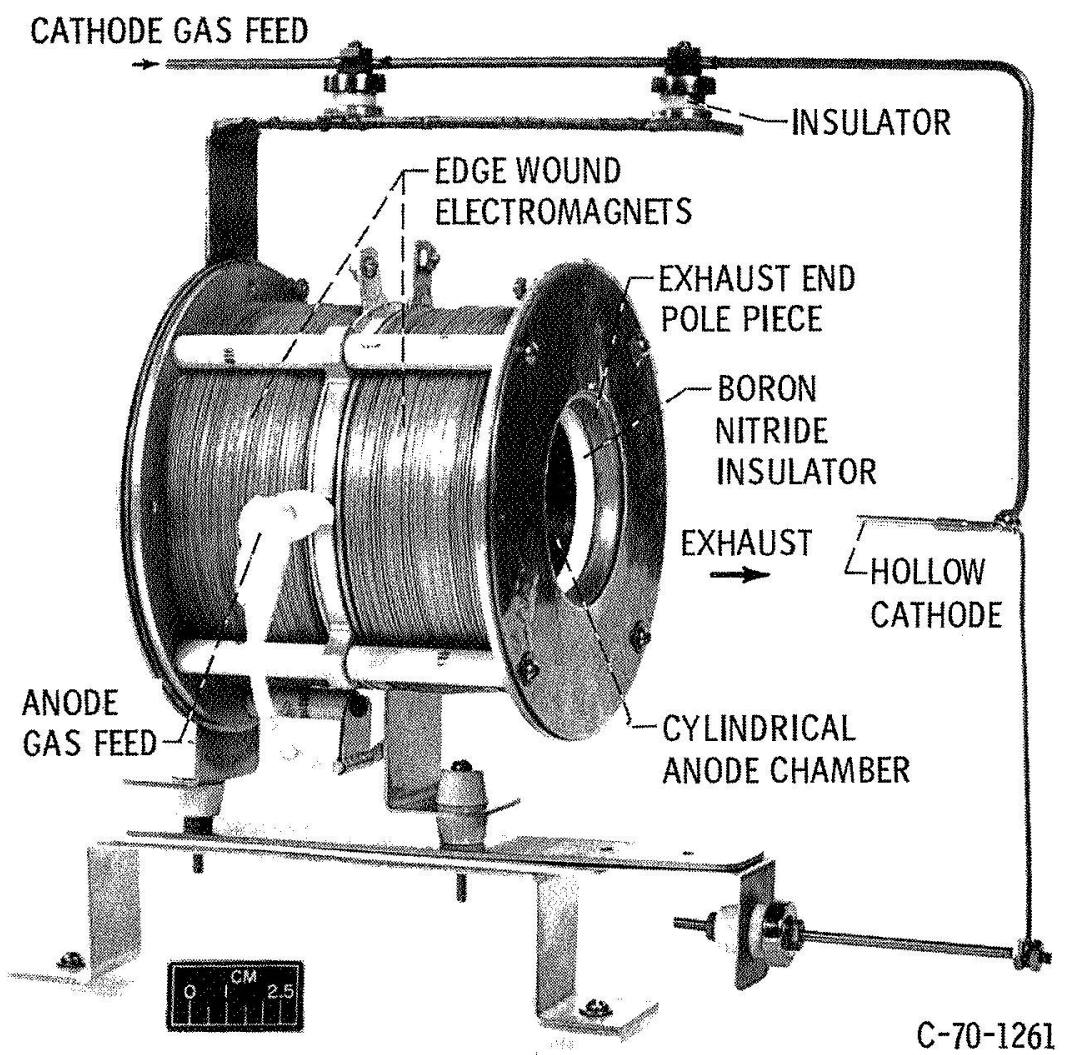

Figure 2. - Low power MPD arc thruster with downstream hollow cathode. This is the thruster tested. 


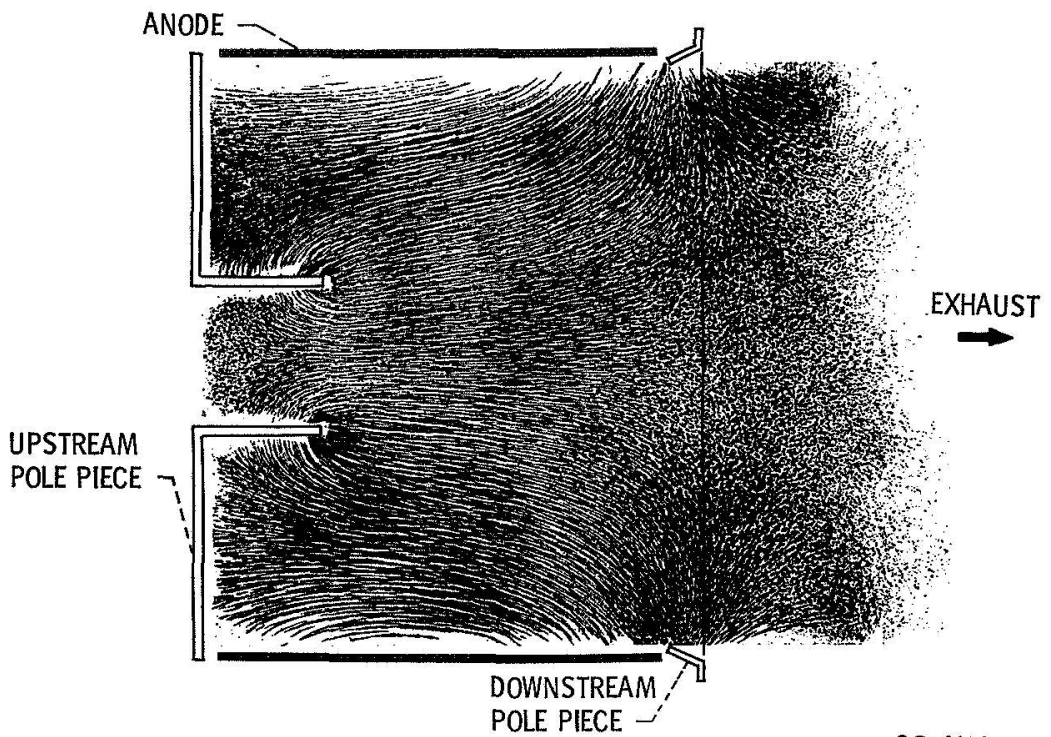

CS-46827

Figure 3. - Map of the magnetic field of a typical discharge chamber with magnetic pole pieces in place. This is for the Sert II electron-bombardment thruster and is taken from reference 3.

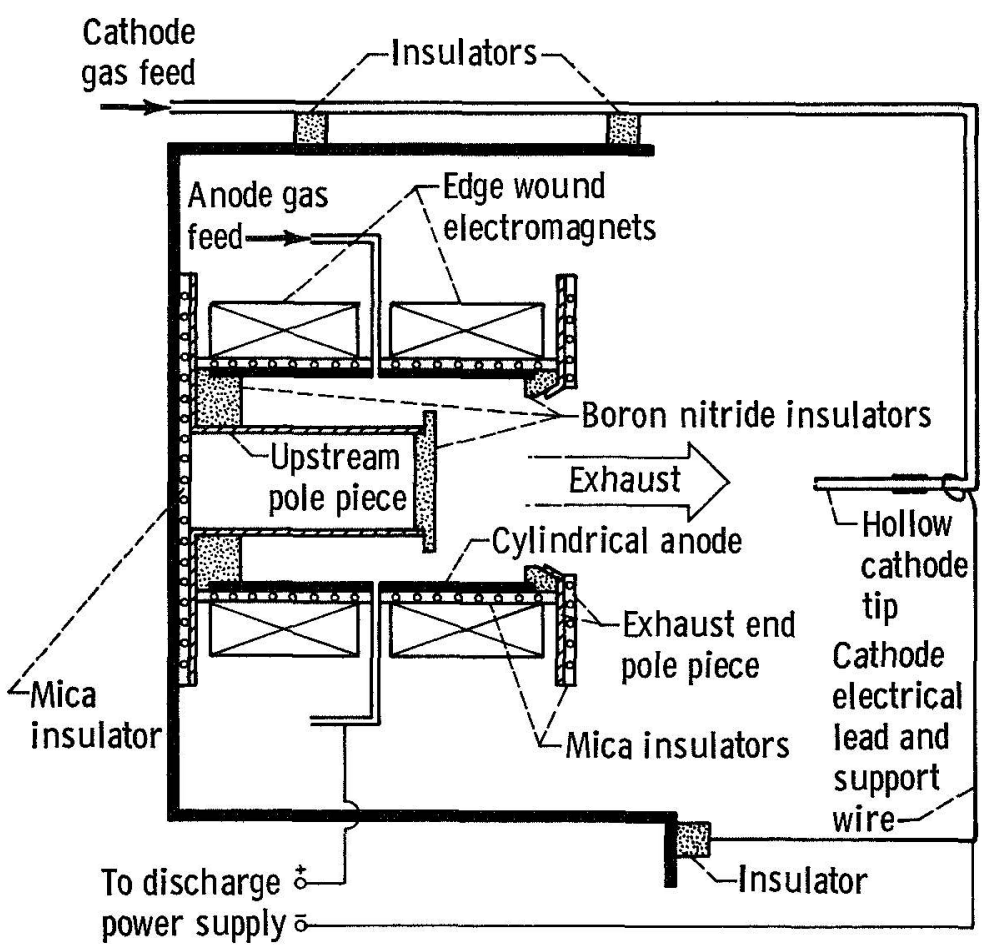

Figure 4. - Schematic of low power MPD arc thruster with a downstream cathode. Cathode tip is $7.62 \mathrm{~cm}$ from exhaust end mica insulator. (Schematic is to scale.) 


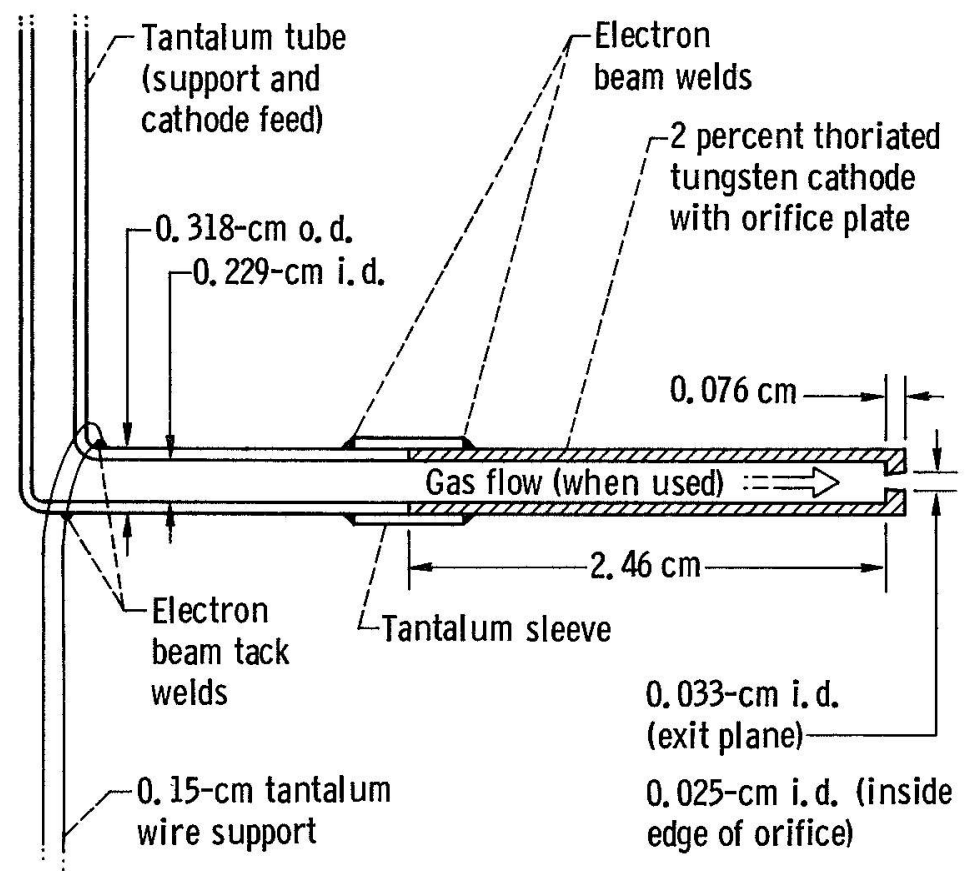

Figure 5. - Cross-sectioned schematic of the 2 percent thoriated tungsten hollow cathode used. Support structure and feed tube also shown.

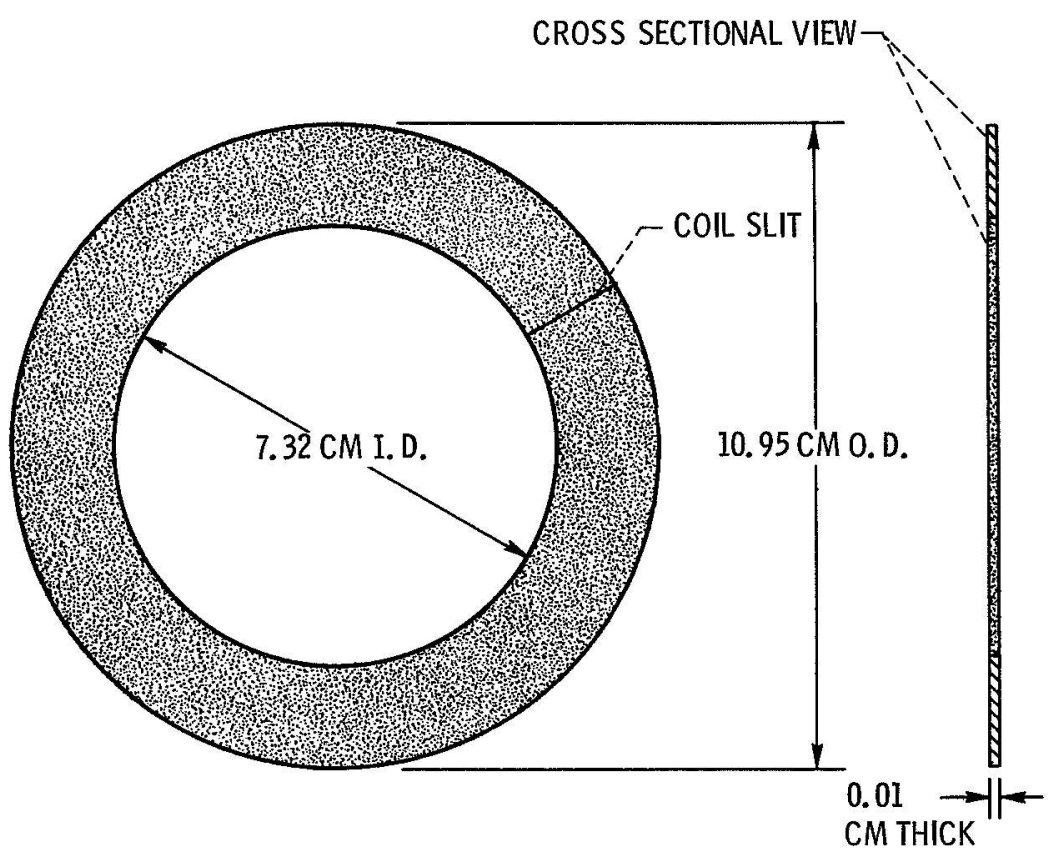

Figure 6. - Sketch showing a single turn of the edge wound electromagnets. 


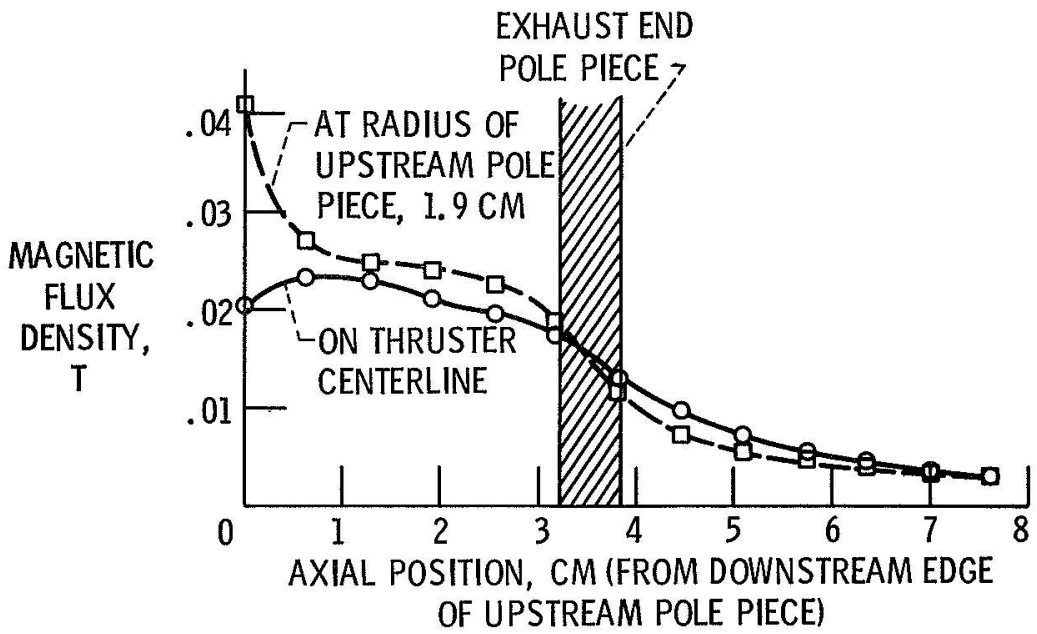

Figure 7. - Plot of axial component of magnetic flux density versus axial position from downstream edge of upstream pole piece. Exhaust end magnet 4.0 amperes (dc) and upstream magnet disconnected.

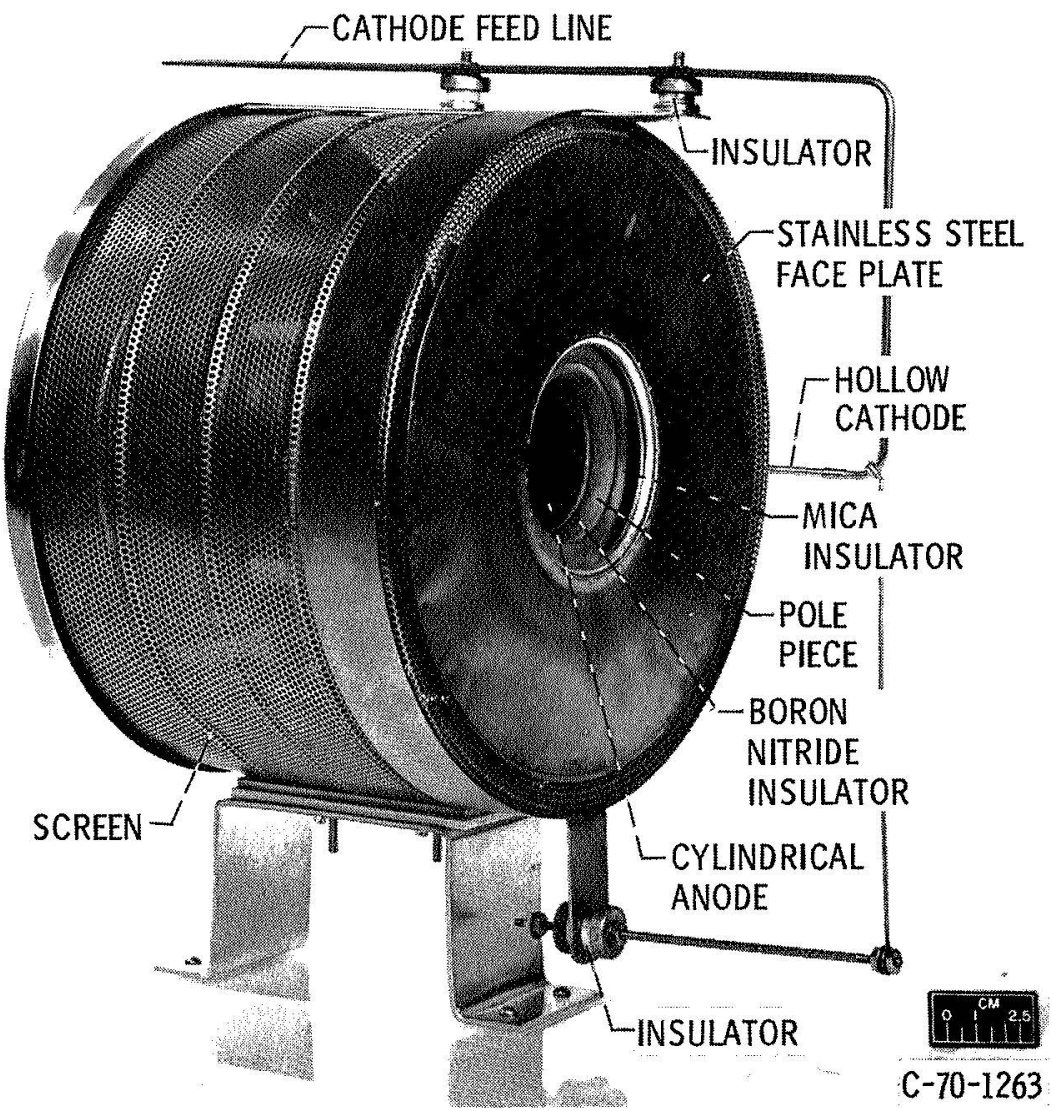

Figure 8. - Downstream cathode MPD thruster with "ground" screen added around magnets and anode. 


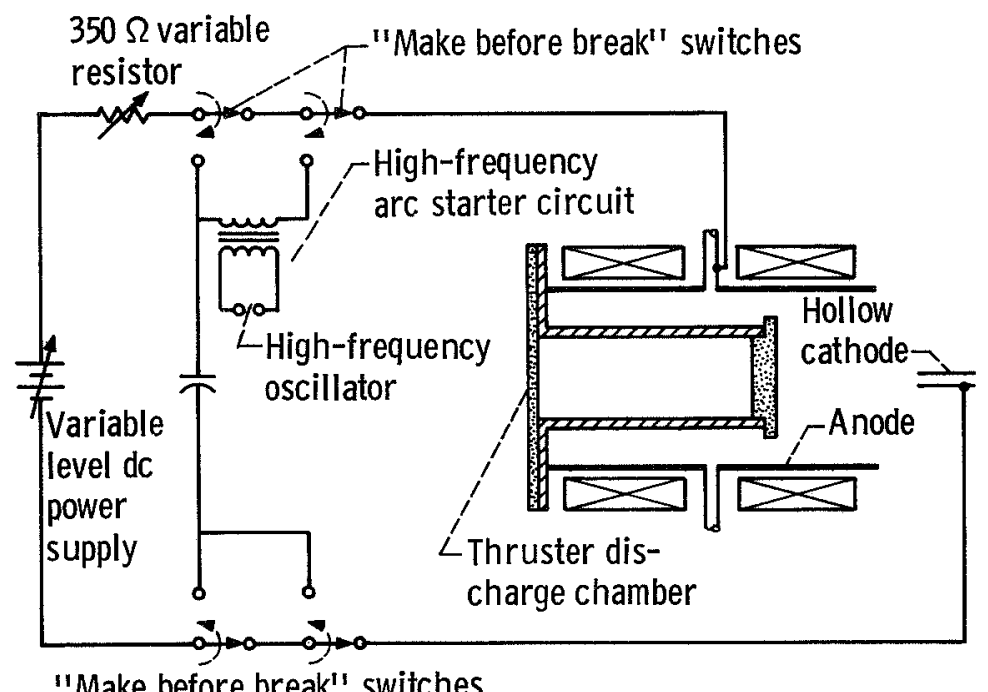

Figure 9. - Schematic of discharge power supply circuit including highfrequency arc starter (shown switched out of circuit). All switches in the circuit are "make before break" type such that contact with the original switch position is maintained while switching to the new position and is then broken after the new contact is completed:

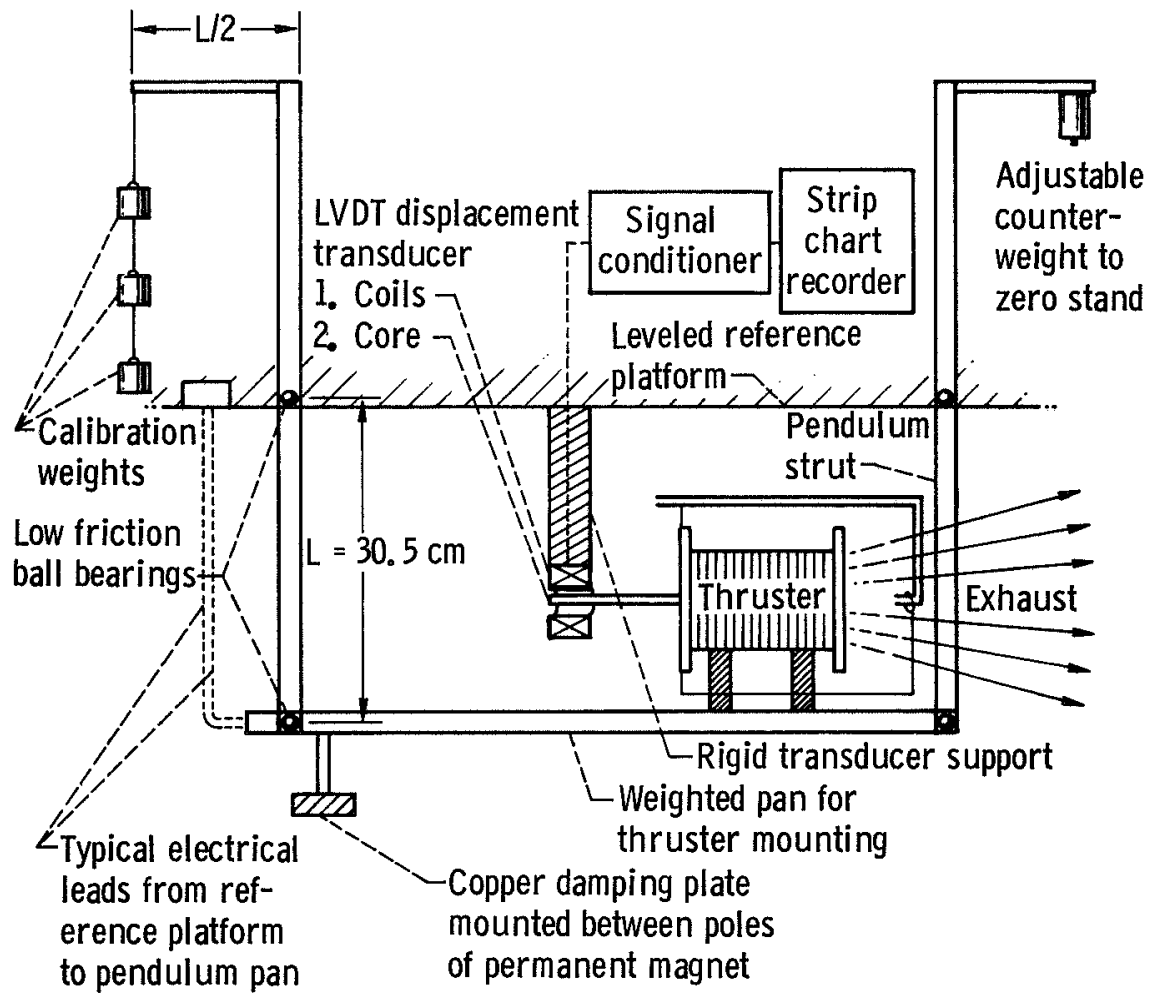

Figure 10. - Schematic of thrust stand used to measure thruster performance. 


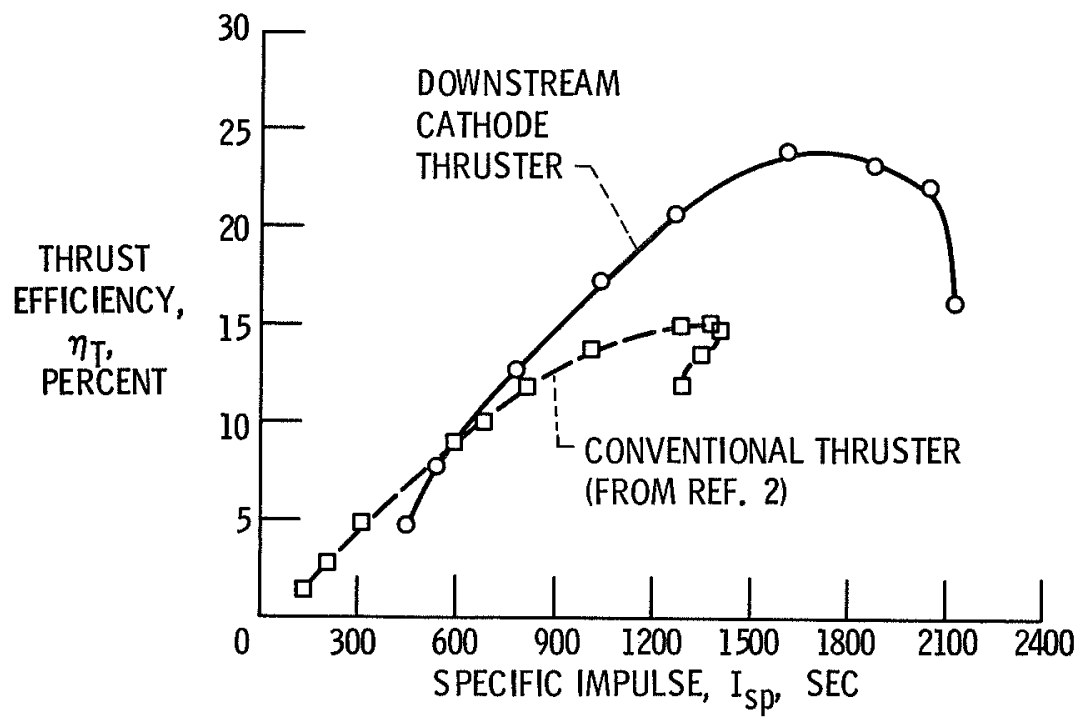

Figure 11. - Plots comparing performance of the two types of low power MPD thrusters with xenon propellant. Downstream cathode thruster is operated with total flow of $0.78 \mathrm{mg} / \mathrm{sec}$, no cathode flow, ground screen attached to cathode and magnetic field 4 amps downstream coil. Conventional thruster operated with $0.58 \mathrm{mg} / \mathrm{sec}$ total flow and cathode flow of 0.06 $\mathrm{mg} / \mathrm{sec}$. Other conditions are reported in reference 2.

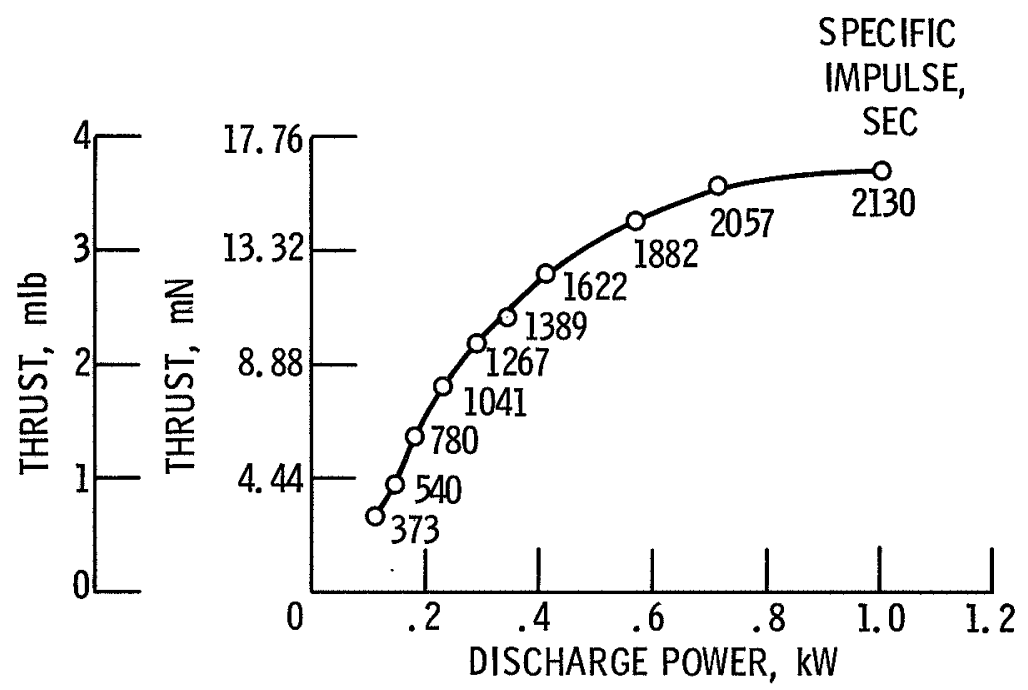

Figure 12. - Thrust versus discharge power for the best thrust efficiency operation obtained with downstream cathode MPD thruster. Total flow of $0.78 \mathrm{mg} / \mathrm{sec}$, no cathode flow, ground screen at cathode potential and magnetic field 4 amps downstream coil. 


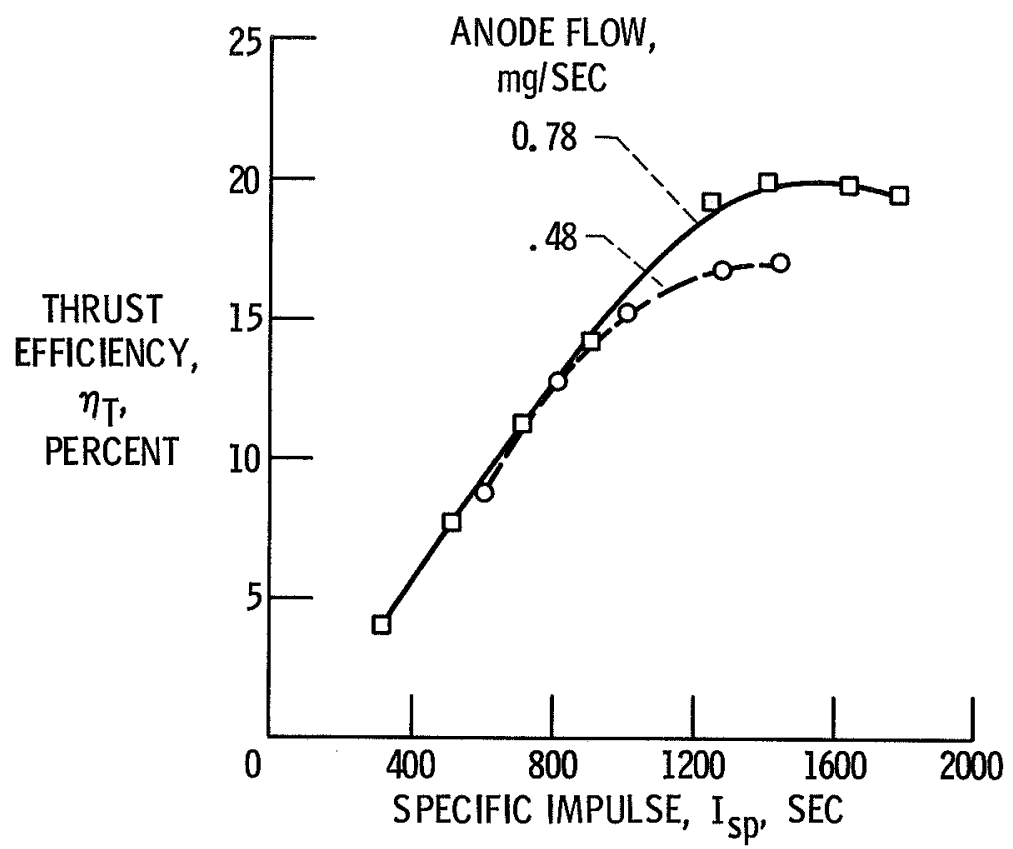

Figure 13. - Thrust efficiency versus specific impulse for two different anode flow rates with cathode flow fixed at $0.09 \mathrm{mg} / \mathrm{sec}$ of xenon. Magnetic field 4 amps downstream coil and no ground screen.

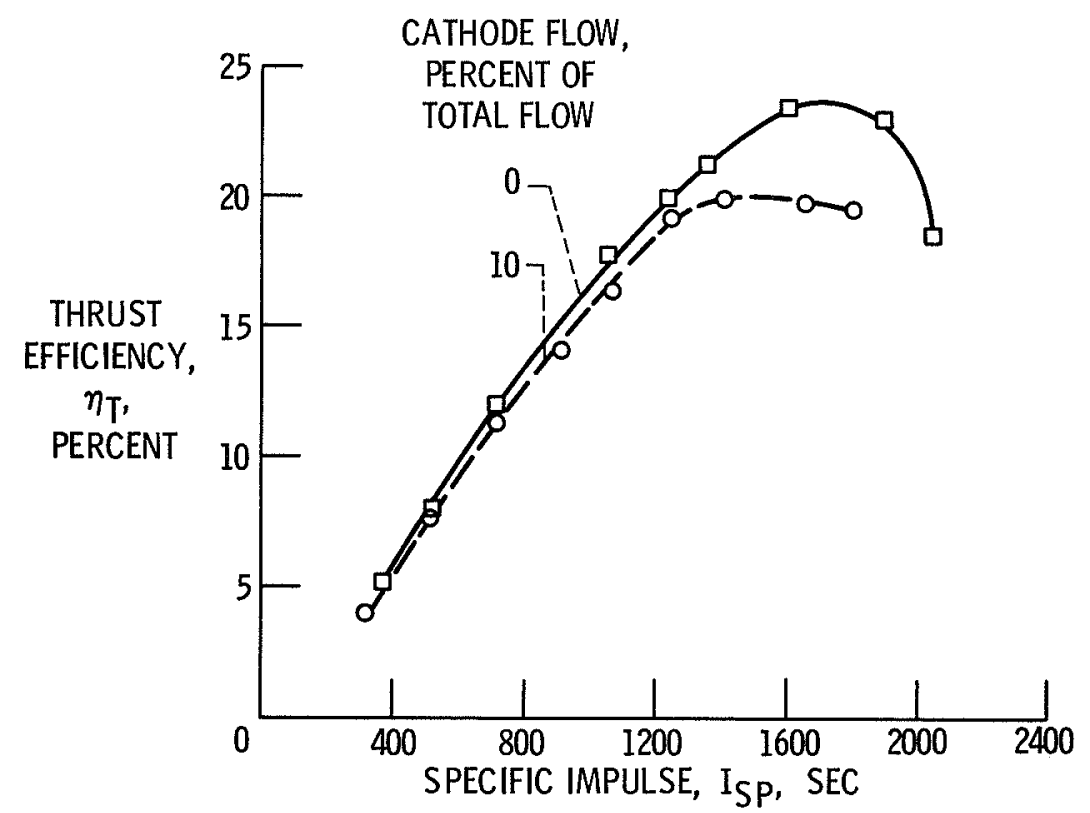

Figure 14. - Thrust efficiency versus specific impulse for a total mass flow rate of $0.87 \mathrm{mg} / \mathrm{sec}$ of xenon with no cathode flow and for cathode flow of $0.09 \mathrm{mg} / \mathrm{sec}$ $\cong 10$ percent of total flow). 


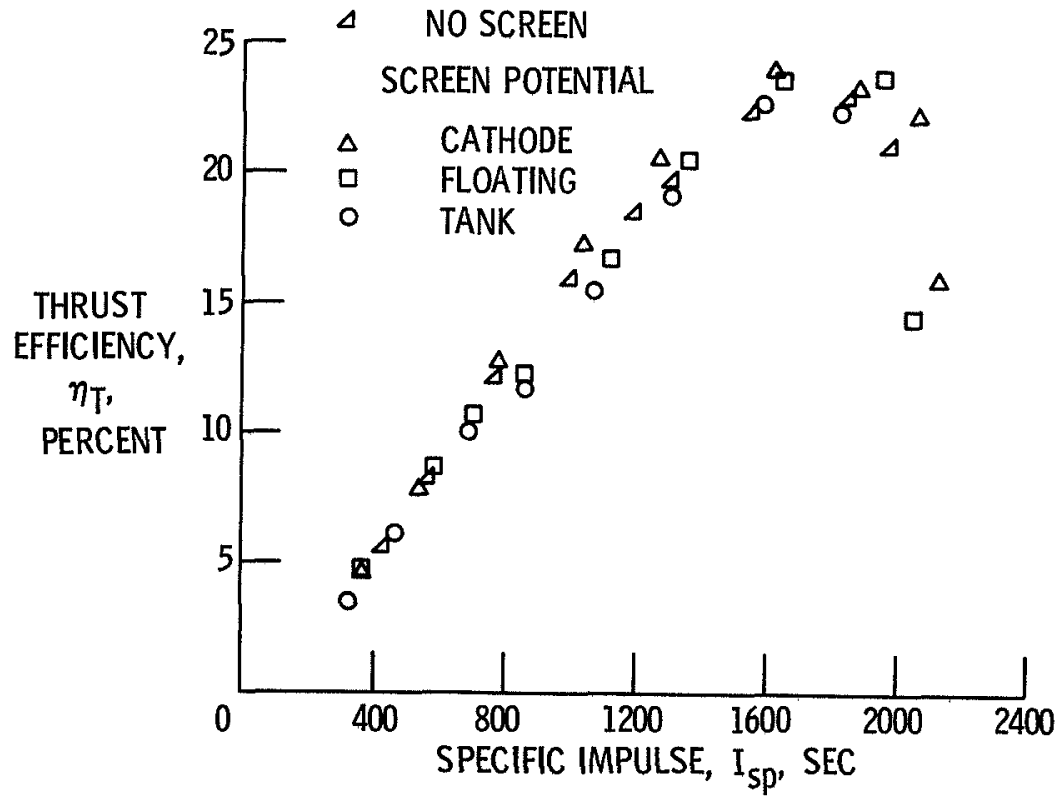

Figure 15. - Thrust efficiency versus specific impulse for three different electrical connections of the ground screen, and for no ground screen at all. Total mass flow of $0.78 \mathrm{mg} / \mathrm{sec}$, no cathode flow and magnetic field with 4 amps downstream coil.

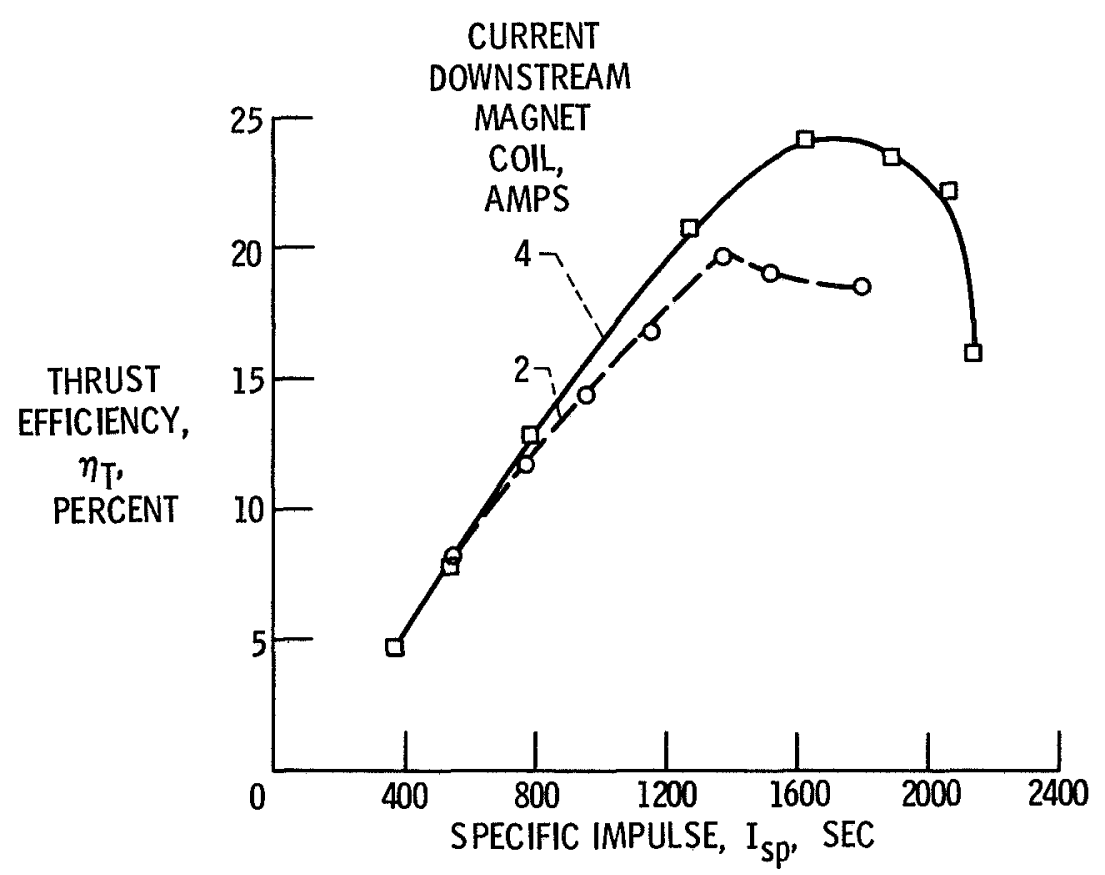

Figure 16. - Thrust efficiency versus specific impulse for two different magnetic field strengths. No cathode flow, total mass flow $0.78 \mathrm{mg} / \mathrm{sec}$, and ground screen at cathode potential. 


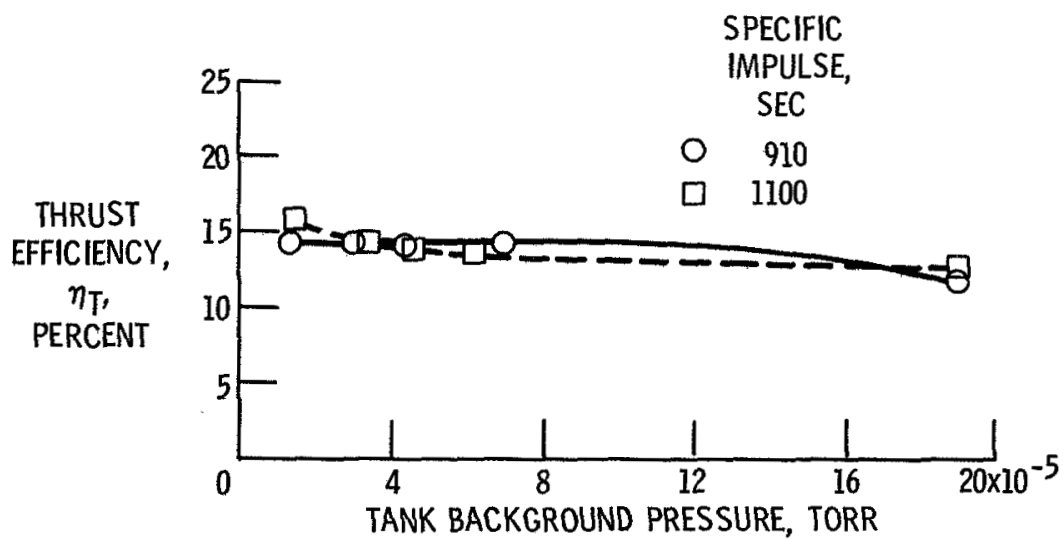

Figure 17. - Variation of thruster efficiency as a function of background pressure at two different operating points. Thruster mass flow $0.78 \mathrm{mg} / \mathrm{sec}$, no cathode flow, ground screen at cathode potential and magnetic field with 4 amps downstream coil. 